\title{
Evaluation of Tigecycline Susceptibility in Multidrug-Resistant Bacteria at the University Hospital of Marrakech (Morocco)
}

\author{
Zemrani Yassin", Ahroui Yassine, Ait Zirri Khadija, Eddyb Saadia, Soraa Nabila \\ Laboratory of Medical Analysis, Microbiology Unit, University Hospital and Faculty of Medicine and Pharmacy, Cadi Ayad University, \\ Marrakech, Morocco \\ Email address: \\ yassinzemrani@gmail.com (Z. Yassin) \\ ${ }^{*}$ Corresponding author
}

\section{To cite this article:}

Zemrani Yassin, Ahroui Yassine, Ait Zirri Khadija, Eddyb Saadia, Soraa Nabila. Evaluation of Tigecycline Susceptibility in MultidrugResistant Bacteria at the University Hospital of Marrakech (Morocco). American Journal of Laboratory Medicine.

Vol. 4, No. 2, 2019, pp. 44-47. doi: 10.11648/j.ajlm.20190402.14

Received: March 16, 2019; Accepted: April 16, 2019; Published: May 17, 2019

\begin{abstract}
The phenomenon of bacterial resistance to antibiotics is a major public health problem. The prevalence of multidrug-resistant bacteria is rapidly increasing with heavy consequences in terms of morbidity and mortality and health care costs. Tigecycline is a new active glycylcycline on this type of germ and could be a therapeutic alternative for the management of these infections. The aim of this work is to evaluate the in vitro activity of Tigecycline against multidrug-resistant organisms isolated at Mohammed VI hospital in Marrakech. It is a descriptive prospective study of a series of 171 multidrug-resistant bacteria including 102 clinical isolates of extended-spectrum $\beta$-lactamase-producing Enterobacteriaceae (ESBL) and 85 clinical isolates of multidrug-resistant Acinetobacter baumannii. The in vitro activity of Tigecycline was measured by the determination of the minimum inhibitory concentration (MIC) by diffusion method on agar medium using the strips "E-test" according to the recommendations of the CASFM. 71\% of Acinetobacter baumannii isolates were sensitive to Tigecycline of with MIC $\leq 1 \mathrm{mg} / 1$, while $17.6 \%$ of tested strains had intermediate sensitivity to Tigecycline with a MIC between 1 and 2 mg / $1,11,4 \%$ were resistant with a MIC $>2 \mathrm{mg} / 1$. ESBL enterobacterial strains were mostly $(77,5 \%)$ with a MIC $\leq 1 \mathrm{mg} / 1$. Intermediate sensitivity was found in $15.6 \%$ of the isolates with a MIC between 1 and $2 \mathrm{mg} / 1$, however, resistance to Tigecycline was found in $6.8 \%$ of enterobacterial isolates with a MIC $>2 \mathrm{mg} / 1$. Tigecycline is an interesting therapeutic option and may have an important role in the treatment of multidrug-resistant infections. Detection of the sensitivity status of Tigecycline is necessary to optimize its use and preserve this molecule in our therapeutic arsenal.
\end{abstract}

Keywords: Tigecycline, Multidrug-Resistant Bacteria, In Vitro Activity

\section{Introduction}

The phenomenon of bacterial resistance to antibiotics is a major public health problem on a global scale. For years, there has been a significant and steady increase in resistance to antibiotics used in the treatment of community and hospital infections [1]. The prevalence of multidrug-resistant bacteria is rapidly increasing with serious consequences in terms of morbidity and mortality and costs of care.

Tigecycline is a new glycylcycline synthetic analogue of tetracyclines. This antibiotic inhibits bacterial protein synthesis by blocking the $30 \mathrm{~S}$ ribosome subunit by attachment to the tRNA binding site. It has been designed that its activity escapes the two main mechanisms of tetracycline resistance that are efflux and ribosomal protection.

In this work, the in vitro activity of Tigecycline is routinely tested against clinically significant isolates of thirdgeneration cephalosporin-resistant enterobacteria by the production of extended-spectrum $\beta$-lactamases and Acinetobacter baumannii.

The aim of this work is to evaluate the in vitro activity of Tigecycline against multidrug-resistant germs isolated at the Mohammed VI hospital in Marrakech for a possible 
therapeutic use.

\section{Patients and Methods}

\subsection{Collection of Clinical Strains}

It's a prospective study on a series of 171 multidrugresistant bacteria, including 102 clinical isolates of extentedspectrum $\beta$-lactamase-producing Enterobacteriaceae (ESBL) and 85 multidrug-resistant clinical isolates of Acinetobacter baumannii, isolated from diagnostic specimens from hospitalized patients presenting with a documented and clinically significant infection in the various hospital departments of the Mohammed VI University Hospital in Marrakech. Inclusion is independent of medical history, previous antibiotic therapy, age and sex. All sampling sites were included.

\subsection{Phenotypic Identification and Determination of Antibiotic Sensitivity}

Enterobacteriaceae and Acinetobacter baumannii were identified according to morphological, cultural and biochemical characters using the BD Phoenix ${ }^{\circledR}$ automaton and / or API 20E, API 20NE (bioMérieux ${ }^{\circledR)}$ galleries according to the methodologies defined by the manufacturer with controls integrated quality. Antibiotic bacterial susceptibility of isolated strains was evaluated using the BD Phoenix ${ }^{\circledR}$ and / or Mueller-Hinton agar (BioRAD $\left.{ }^{\circledR}\right)$. The distinction between ESBL and high-level cephalosporinase was carried out by the synergy test between third-generation cephalosporin disks and an amoxicillin / clavulanic acid disc according to the recommendations of the Committee of the antibiogram of the French Society of microbiology.

The in vitro activity of Tigecycline was measured by the determination of the minimum inhibitory concentration by diffusion method on agar medium using the strips "E-test" according to the recommendations of the CASFM.

\section{Results}

\subsection{Epidemiology of the Strains Collected}

Susceptibility to Tigecycline was tested on 102 enterobacterial strains including 56 strains of Klebsiella pneumoniae (55\%), 30 strains of Enterobacter cloacae (29.4\%), and 16 strains of Escherichia coli (15.6\%). These strains were isolated mainly from blood cultures $(39.2 \%)$, urinary samples (30.4\%), various suppurated samples $(22.5 \%)$ and respiratory samples $(7.7 \%)$. The majority of these strains were isolated from intensive care units (47\%), $29.4 \%$ from surgical departments, $19.6 \%$ from medical services and $4 \%$ of the strains were isolated in emergency services.

The 85 multidrug-resistant strains of Acinetobacter baumannii were isolated from blood cultures (33\%), respiratory samples $(20 \%)$ from urinary samples (14\%) and various suppurated samples $(33 \%) .7 \%$ of the patients were hospitalized in medical services, $81 \%$ in intensive care units, and $12 \%$ in surgical services.

\subsection{Tigecycline Susceptibility of C3G Resistant Enterobacteriaceae}

The results of multidrug-resistant enterobacterial isolates showed that the majority of strains, $77.5 \%$, were considered sensitive with a MIC of $\leq 1 \mathrm{mg} / 1$. In the different species, Escherichia coli was the most frequently susceptible species in the enterobacteriaceae group with $100 \%$ sensitivity. For Enterobacter cloacae, the percentage of susceptible strains was lower $(86.7 \%)$. This sensitivity was more reduced in Klebsiella pneumoniae isolates where a sensitivity of $69.8 \%$ was observed. Resistant or intermediate susceptibility strains were isolated mainly in intensive care units $(60 \%)$. (Table 1$)$

Table 1. Sensitivity profile of ESBL Enterobacteriaceae to Tigecycline by Infectious Site and by Service.

\begin{tabular}{|c|c|c|c|c|c|}
\hline $\begin{array}{l}\text { Sensitivity of EBs } \\
\text { to TGC }\end{array}$ & $\begin{array}{l}\text { No. of } \\
\text { isolates }\end{array}$ & $\%$ & $\begin{array}{l}\text { Bacterial species (\% of Sensitivity } \\
\text { within the species) }\end{array}$ & Hospitalization services & Collection sites \\
\hline $\begin{array}{l}\text { Sensitive } \\
M I C \leq 1 \mathrm{mg} / \mathrm{L}\end{array}$ & 79 & $77,5 \%$ & $\begin{array}{l}16 \text { E. coli }(100 \% \text { sensitivity) } \\
37 \text { K. pneumoniae }(66 \% \text { sensitivity) } \\
26 \text { E. cloacae }(86,7 \% \text { sensitivity) }\end{array}$ & $\begin{array}{l}\text { ICU: } 34 \text { isolates }(43 \%) \\
\text { surg: } 26 \text { isolates }(32,9 \%) \\
\text { Med: } 16 \text { isolates }(20,3 \%) \\
\text { Emerg: } 3 \text { isolates }(3,8 \%)\end{array}$ & $\begin{array}{l}\text { Blood culture: } 33 \text { isolates }(41,7 \%) \\
\text { Pus: } 17 \text { isolates }(21,5 \%) \\
\text { Respiratory: } 6 \text { isolates }(7,7 \%) \\
\text { Urinary: } 23 \text { isolates }(29,1 \%)\end{array}$ \\
\hline $\begin{array}{l}\text { Intermediate } \\
1 \mathrm{mg} / L \leq M I C \leq 2 \\
m g L\end{array}$ & 16 & $15,7 \%$ & $\begin{array}{l}12 \mathrm{~K} \text {. pneumoniae }(21,4 \% \\
\text { intermediate sensitivity) } \\
4 \text { E. cloacae }(13,3 \% \text { intermediate } \\
\text { sensitivity) }\end{array}$ & $\begin{array}{l}\text { ICU: } 9 \text { isolates }(56,3 \%) \\
\text { Surg: } 3 \text { isolates }(18,7 \%) \\
\text { Med: } 3 \text { isolates }(18,7 \%) \\
\text { Emerg: } 1 \text { isolat }(6,3 \%)\end{array}$ & $\begin{array}{l}\text { Blood culture: } 4 \text { isolates }(25 \%) \\
\text { Pus: } 5 \text { isolates }(31,2 \%) \\
\text { Respiratory: } 1 \text { isolates }(6,3 \%) \\
\text { Urinary: } 6 \text { isolates }(37,5 \%)\end{array}$ \\
\hline $\begin{array}{l}\text { Resistant } \\
M I C \leq 2 \mathrm{mg} / L\end{array}$ & 7 & $6,8 \%$ & $7 \mathrm{~K}$. pneumoniae $(12,6 \%$ resistance $)$ & $\begin{array}{l}\text { ICU: } 5 \text { isolates }(71,4 \%) \\
\text { Surg: } 1 \text { isolate }(14,3 \%) \\
\text { Med: } 1 \text { isolate }(14,3 \%)\end{array}$ & $\begin{array}{l}\text { Blood culture: } 3 \text { isolates }(42,8 \%) \\
\text { Pus: } 1 \text { isolat }(14,3 \%) \\
\text { Respiratory: } 1 \text { isolate }(14,3 \%) \\
\text { Urinary: } 2 \text { isolates }(28,6 \%)\end{array}$ \\
\hline
\end{tabular}

EB: enterobacteriaceae; TGC: Tigecycline; E. coli: Escherichia coli; K. pneumoniae: Klebsiella pneumonia; E. cloacae: Enterobacter cloacae; ICU: intensive care unit; Surg: Surgery; Med: Medicine; Emerg: Emergency

\subsection{Tigecycline Sensitivity of Multidrug-Resistant Acinetobacter Baumannii Strains}

This study included 85 strains of Acinetobacter baumannii; Sensitivity to Tigecycline was found in $71 \%$ of
Acinetobacter baumannii isolates with MIC $\leq 1 \mathrm{mg} / 1$. $17.6 \%$ of the strains tested had an intermediate sensitivity to Tigecycline with a MIC between 1 and $2 \mathrm{mg} / 1.11 .4 \%$ of isolates were resistant with a MIC $>2 \mathrm{mg} / 1$. Tigecycline- 
resistant and intermediate susceptibility strains were isolated mainly from burns, bacteremia, and acquired pneumonia under mechanical ventilation in the intensive care unit (Table 2).

Table 2. Profile of the susceptibility of Acinetobacter baumannii strains to Tigecycline by infectious site and by service.

\begin{tabular}{|c|c|c|c|c|}
\hline Sensitivity to TGC & Number of $A B$ isolates & $\%$ & Hospitalization services & Collection sites \\
\hline $\begin{array}{l}\text { Sensitive } \\
\mathrm{MIC} \leq 1 \mathrm{mg} / \mathrm{L}\end{array}$ & 60 & $71 \%$ & $\begin{array}{l}\text { ICU: } 48 \text { isolates }(80 \%) \\
\text { Surgery: } 7 \text { isolates }(11,7 \%) \\
\text { Medicine: } 5 \text { isolates }(8,3 \%)\end{array}$ & $\begin{array}{l}\text { Blood culture: } 21 \text { isolates }(35 \%) \\
\text { Pus: } 23 \text { isolates }(38,3 \%) \\
\text { Respiratory: } 10 \text { isolates }(16,7 \%) \\
\text { Urinary: } 6 \text { isolates }(10 \%)\end{array}$ \\
\hline $\begin{array}{l}\text { Intermediate } \\
1 \mathrm{mg} / \mathrm{L} \leq \mathrm{MIC} \leq 2 \mathrm{mg} \mathrm{L}\end{array}$ & 15 & $17,6 \%$ & $\begin{array}{l}\text { ICU: } 12 \text { isolates }(80 \%) \\
\text { Surgery: } 2 \text { isolates }(13,3 \%) \\
\text { Medicine: } 1 \text { isolates }(6,7 \%)\end{array}$ & $\begin{array}{l}\text { Blood culture: } 4 \text { isolates }(26,7 \%) \\
\text { Pus: } 3 \text { isolates }(20 \%) \\
\text { Respiratory: } 3 \text { isolates }(20 \%) \\
\text { Urinary: } 5 \text { isolates }(33,3 \%)\end{array}$ \\
\hline $\begin{array}{l}\text { Resistant } \\
\mathrm{MIC} \leq 2 \mathrm{mg} / \mathrm{L}\end{array}$ & 10 & $11,4 \%$ & $\begin{array}{l}\text { ICU: } 9 \text { isolates }(90 \%) \\
\text { Surgery: } 1 \text { isolates }(10 \%)\end{array}$ & $\begin{array}{l}\text { Blood culture: } 3 \text { isolates }(30 \%) \\
\text { Pus: } 2 \text { isolates }(20 \%) \\
\text { Respiratory: } 4 \text { isolates }(40 \%) \\
\text { Urinary: } 1 \text { isolates }(10 \%)\end{array}$ \\
\hline
\end{tabular}

TGC: Tigecycline; AB: Acinetobacter baumannii; ICU: intensive care unit

\section{Discussion}

Increasing bacterial resistance to antibiotics continues to grow and can lead to therapeutic impasses. This phenomenon sometimes seriously limits the number of anti-infective agents available in the therapeutic arsenal and can be particularly problematic in severe infections and in high-risk patients [2].

Tigecycline is a recent antibiotic, a semi-synthetic derivative of minocycline belonging to the glycycline class, with a large spectrum of activity against difficult-to-treat pathogens, such as Acinetobacter baumannii and Gramnegative bacterial strains producing extended spectrum $\beta$ lactamases. Its advantage lies in its high power of action and in its escape to the two main mechanisms of resistance to tetracyclines, the protection of ribosomes and efflux. Minimal organic toxicity and lack of dosage adjustment in most patients are important considerations for the use of Tigecycline. It has been shown to be as effective and safe as standard antimicrobial therapy for the treatment of complicated intra-abdominal infections of adults, complex skin conditions and skin structure infections, and bacterial pneumonia acquired in the community. [3]. Tigecycline resistance mechanisms are mainly associated with RND (resistance-nodulation-division division) transporters: the AdeABC, AdeFGH and AdeIJK efflux pumps, but other resistance mechanisms have also been implicated. [4, 5]

ESBL-producing enterobacteriaceae, since their first description in the 1980s, have caused numerous epidemics at the local, regional and international levels, frequently having as origin the resuscitation services. The commensal nature of these bacteria and the plasmid genetic support of the mechanism of resistance have allowed their spread on a very large scale. The infections caused by these strains present an increased risk of therapeutic failure and are associated to prolonged hospitalizations and additional costs related to care. Tigecycline is a therapeutic alternative to eradicate these multiresistant strains. This study confirms a good activity of Tigecycline on ESBL enterobacteriaceae with a sensitivity reaching $77.5 \%$ on all strains tested. The most effective efficacy is observed in isolates of Escherichia coli with $100 \%$ sensitivity, this sensitivity decreases in Enterobacter and Klebsiella (respectively $86.7 \%$ and $66 \%$ sensitivity) which is consistent with data from the literature [6-8]

Acinetobacter baumannii is a pathogen of increasing concern, usually causing epidemics in hospitals. It has many resistance mechanisms and may be involved in therapeutic impasse situations. In this study, the Acinetobacter baumannii strains have a sensitivity of $71 \%$ to Tigecycline. This sensitivity could be interesting in therapeutics because of the increase in the frequency of antibiotic-resistant Acinetobacter baumannii infections [9]. However, the high frequency of intermediate sensitivity Acinetobacter baumannii strains or resistant ones to Tigecycline $(17.6 \%$ and $11.4 \%$ respectively) can be explained by the non-rational use of antibiotics, especially in intensive care unit. [10].

Although the use of Tigecycline in case of multidrugresistant infection is an attractive choice, the prescription should be made with caution as therapeutic failures have been reported mainly in strains of Acinetobacter baumannii [11]. Dual antibiotic therapy with Tigecycline has become an attractive option for clinicians. Combination antibiotic therapy suggestions are being studied in vitro with moderate synergistic results that may suppress Tigecycline resistance, which should be confirmed in animal models and clinical trials $[12,13]$.

\section{Conclusion}

This study reports the emergence of Tigecycline resistance in isolates of Klebsiella pneumoniae, Enterobacter cloacae and Acinetobacter baumannii in our context. The treatment of multidrug-resistant infections is a real challenge for the clinician, and the therapeutic experience with these germs is limited. Tigecycline is an interesting therapeutic option and may have an important place in the treatment of these infections. Accurate detection of Tigecycline-sensitive status and surveillance of resistant organisms in hospitals is necessary to optimize its prescription and preserve this molecule in our therapeutic arsenal. However, its use would 
require clarification of the sensitivity threshold and better knowledge of the correlation between in vitro and in vivo activity.

\section{References}

[1] Ramirez A. Controlling multiple-drug-resistant organisms at the hospital level. Expert Opin Pharmacother 2006; 7: 144955.

[2] Masterton R, Drusano G, Paterson DL, Park G. Appropriate antimicrobial treatment in nosocomial infections-the clinical challenges. J Hosp Infect 2003; 55 (Suppl 1): 1-12.

[3] Stein GE, Babinchak T. Tigecycline: an update. Diagnostic Microbiology and Infectious Disease Volume 75, Issue 4, April 2013, Pages 331-336.

[4] Pournaras S, Koumaki V, Gennimata V, Kouskouni E, Tsakris A. In Vitro Activity of Tigecycline Against Acinetobacter baumannii: Global Epidemiology and Resistance Mechanisms. Adv Exp Med Biol. 2016; 897: 1-14.

[5] Yan Sun, Yun Cai, Xu Liu, Nan Bai, Beibei Liang, Rui Wang. The emergence of clinical resistance to tigecycline. International Journal of Antimicrobial Agents 41 (2013): 110 116.

[6] C. Bris, G. Auger, F. Kowalczyk, M. Eveillard, M.-L. JolyGuillou, M. Kempf. Activité in vitro de la Tigécycline vis-àvis de 760 souches bactériennes isolées au CHU d'Angers-le programme TEST 2006-2009 pathologie Biologie 60 (2012): 336-339.

[7] Y. Rio, P. Okamba, A. Staal, J. Didion, F. Jurin. Activité in vitro de la Tigécycline vis-à-vis des germes pathogènes isolés d'infections respiratoires en Europe. Le programme TEST 2004-2007. Pathol Biol 2009; 57: 13-6.

[8] Kelesidis T, Karageorgopoulos DE, Kelesidis I, Falagas ME. Tigecycline for the treatment of multidrug-resistant Enterobacteriaceae: a systematic review of the evidence from microbiological and clinical studies. J Antimicrob Chemother. 2008 Nov; 62 (5): 895-904.

[9] Kempf M, Rolain JM. Emergence of resistance to carbapenems in Acinetobacter baumannii in Europe: clinical impact and therapeutic options. Int J Antimicrob Agents 2011.

[10] Park GE, Kang CI, Cha MK, Cho SY, Seok H, Lee JH, Kim JY, Ha YE, Chung DR, Peck KR, Lee NY, Song JH. Bloodstream infections caused by Acinetobacter species with reduced susceptibility to tigecycline: clinical features and risk factors. Int J Infect Dis. 2017 Sep; 62: 26-31.

[11] Gordon NC, Wareham DW. A review of clinical and microbiological outcomes following treatment of infections involving multidrug-resistant Acinetobacter baumannii with tigecycline. J Antimicrob Chemother 2009; 63: 775-80.

[12] Yee-Huang Ku. Chi-Chung Chen. Mei-Feng Lee. Yin-Ching Chuang. Hung-Jen Tang. Wen-Liang Yu. Comparison of synergism between colistin, fosfomycin and tigecycline against extended-spectrum $\beta$-lactamase-producing Klebsiella pneumoniae isolates or with carbapenem resistance. Journal of Microbiology, Immunology and Infection Volume 50, Issue 6, December 2017, Pages 931-939.

[13] Li J, Yang X, Chen L, Duan X, Jiang Z. In Vitro Activity of Various Antibiotics in Combination with Tigecycline Against Acinetobacter baumannii: A Systematic Review and MetaAnalysis. Microb Drug Resist. 2017 Dec; 23 (8): 982-993. 